\title{
Association of Preoperative HbA1c Level with Incidence of New-onset Atrial Fibrillation during Early Postoperative Period after Off-Pump Coronary Artery Bypass Grafting Surgery in Diabetic Patients
}

\author{
Md. Jilhaj Uddin', A. K. M. Manzurul Alam¹, AM Asif Rahim², AYM Shahidullah³, \\ ASM Iftekher Hossain ${ }^{2}$, Manzil Ahmad", \\ ${ }^{1}$ National Institute of Cardiovascular Diseases, Dhaka, ${ }^{2}$ Chattogram Medical College, Chattogram, \\ ${ }^{3}$ Fortis Escort Heart Institute, Khulna
}

Key Words : Atrial fibrillation, diabetes mellitus, $H b A 1 c, I H D$, $O P C A B$.

\begin{abstract}
:
Background: Diabetes mellitus is an independent risk factor for coronary artery disease and it adversely affects the postoperative outcome after CABG surgery. Adequate control of diabetes for a longer period, which can be assessed by HbA1c, before OPCAB may reduce development of postoperative atrial fibrillation and thus improve outcome.

Methods: This was an observational study included sixty diabetic patients purposively who underwent isolated off pump coronary artery bypass procedure in NICVD. Total sample contained 60 diabetic patients, which were divided in two equal groups. Grouping was Group I-30 Diabetic patients with preoperative HbA1c $<7 \%$ and Group II - 30 Diabetic patients with preoperative HbA1c $\geq 7 \%$ and all of whom underwent isolated OPCAB. Postoperative atrial fibrillation and other complications were recorded and compared in two groups of patients.

Results: Most postoperative atrial fibrillation (AF) developed in higher age group 61-70 years (61.5\%). Postoperative complications were higher in group II. Postoperative AF was significantly higher in diabetic patients having preoperative HbA1c $\geq 7 \%$ compare to diabetic patients with HbA1c $<7 \%$ in early postoperative period after OPCAB. Age (61-70 years) (OR=1.872, $p=0.018)$, preoperative HbA1c $\geq 7 \%(O R=19.029, p=0.002)$ and hypertension $(O R=1.091, p=0.019)$ was found significantly associated with increased development of postoperative atrial fibrillation.

Conclusion: Our study revealed that higher preoperative HbAlc level was associated with increased incidence of new onset atrial fibrillation after OPCAB. So, it can be used as a reliable indicator for adequate control of diabetes preoperatively among patients selected for isolated elective OPCAB in future.
\end{abstract}

(Cardiovasc. j. 2020; 12(2): 113-119)

\section{Introduction:}

Diabetes mellitus (DM) is an ever-raising costly chronic diseases worldwide. A global observatory projection estimated that $7.7 \%$ of world population will have diabetes by 2030 . It increases the risk of coronary artery disease by $2-4$ folds. ${ }^{1}$ Patients having diabetes with multi-vessel disease, coronary artery bypass surgery (CABG) may be the preferred mode of myocardial revascularization for better long-term outcome. ${ }^{2}$ Actually $20 \%$-30\% of the patients undergoing coronary artery bypass have diabetes mellitus. ${ }^{3}$ In spite of conventional CABG being the gold standard method, off-pump technique (OPCAB) is a safe and effective

Address of Correspondence: Dr. Md. Jilhaj Uddin, Department of Cardiac Surgery, National Institute of Cardiovascular Diseases, Dhaka, Bangladesh. Email-

๑ 2020 authors; licensed and published by International Society of Cardiovascular Ultrasound, Bangladesh Chapter and Bangladesh Society of Geriatric Cardiology. This is an Open Access article distributed under the terms of the CC BY NC 4.0 (https://creativecommons.org/licenses/by-nc/4.0). 
alternative to reduce postoperative complications for these patients. Nevertheless, chronic uncontrolled state of diabetes significantly increases the postoperative complications after OPCAB also. ${ }^{4}$ Therefore, early diagnosis and treatment of DM is of utmost important to prevent diabetes associated postoperative complications and to improve short- and long-term outcome after OPCAB ${ }^{5}$

HbA1c level is used as the standard method for assessing long term glycemic control in diabetic patients. ${ }^{6}$ According to the revised based guideline of American Diabetic Association (ADA), blood HbA1c level $\leq 5.7 \%$ indicates the absence of diabetes, 5.7\%-6.45\% indicates pre-diabetes, and $6.5 \%$ or higher is considered as diabetes. ${ }^{7}$ The ADA has recommended $\mathrm{HbA} 1 \mathrm{c}$ level lower than 7\% for diabetic patients to reduce diabetes associated complications.

After OPCAB surgery, various postoperative events like arrhythmia, heart failure or stroke may complicate the early postoperative period; and atrial fibrillation is fairly a common complication among them which may increase mortality, morbidity as well as burden on national health care cost. ${ }^{8}$ In 2016 Surer et al has shown that occurrence of $\mathrm{AF}$ in controlled diabetes versus uncontrolled diabetic groups after OPCAB is $15.3 \%$ and $57.1 \%$ respectively. Actually, the preoperative control status of DM, reflected by HbA1c level, correlates well with the incidence of atrial fibrillation during early postoperative period after OPCAB.$^{9}$

Atrial fibrillation is often a short-lived and selflimiting condition but can results in debilitating and even lethal consequences like post-operative MI, stroke, hemodynamic instability or sudden cardiac death. ${ }^{10}$ Though hypertension, heart failure, valvular heart disease and electrolytes imbalance are considered as independent factors for atrial fibrillation, its development is likely to be multifactorial and mechanism is still nonconclusive. Recently some other factors including diabetes are also being blamed for this undue event. ${ }^{11}$

There are emerging evidences on the association of atrial fibrillation and diabetes. Liu et al have shown that diabetes mellitus is strongly associated with early post-OPCAB new-onset atrial fibrillation. Prolonged uncontrolled diabetes in preoperative period influences the development of AF through diverge ways. The remodeling processes taken place here are- i) oxidative stress in tissues and organs leading to atrial electrical remodeling producing abnormality in rhythm generation, ii) atrial structural remodeling causing altered atrial conduction time and impaired cardiac mechanics and also iii) autonomic remodeling causing autonomic dysfunction. ${ }^{11}$

Improper preoperative diabetes control is common among patients selected for OPCAB. In developing countries like ours it is more common due to lack of knowledge and awareness. A good number of studies have examined the $\mathrm{HbA} 1 \mathrm{c}$ as a predictor of atrial fibrillation after on-pump CABG, but study in relation to OPCAB is inadequate. So, the proposed study seems to be quite reasonable and time worthy.

\section{Methods:}

This is an Observational study with a group comparison design done in Department of Cardiac surgery, National Institute of Cardiovascular Diseases (NICVD), Dhaka during the period between April, 2017 to September, 2018. It was a Purposive sampling. Study population were Diabetic patients underwent isolated off pump coronary artery bypass surgery in NICVD. With Inclusion criteria of Diabetic patients with sinus rhythm who underwent isolated OPCAB surgery and age between 30 years and 70 years Exclusion criteria were Left ventricular systolic dysfunction (LVEF <35\%), history of use of antiarrhythmic device or drugs except beta blocker, emergency surgery, redo surgery and conversion to on-pump CABG. Grouping of the patient were done with Group I - 30 Diabetic patients with HbA1c $<7 \%$ undergone OPCAB surgery and Group II - 30 Diabetic patients with $\mathrm{HbA} 1 \mathrm{c} \geq 7 \%$ undergone OPCAB surgery. Informed written consent was taken from each patient before enrollment. Meticulous history and detailed clinical examination findings were recorded in predesigned structured format. Preoperative HbA1c levels were measured using Beckman Coulter Au480 at SSMCH. Records regarding previous arrhythmia were analyzed. Preoperative 12-lead ECG should be taken on admission. 
All patients were switched on subcutaneous short acting insulin 48 hours preoperatively to achieve blood glucose around $110 \mathrm{mg} / \mathrm{dl}(6.1 \mathrm{mmol} / \mathrm{L})$. Preoperative blood glucose was checked before each meal three times daily and insulin dose was adjusted accordingly. Intraoperative management included serial measurement of blood glucose every 30-60 minutes and intravenous insulin to maintain target serum glucose within $110 \mathrm{mg}-216 \mathrm{mg} / \mathrm{dl}$ (6$12 \mathrm{mmol} / \mathrm{L})$. During postoperative ICU stay, normoglycemia was achieved following 'Hyperglycemia Protocol for Cardiac Surgery Patient' with a targeted blood glucose level between 110 and $150 \mathrm{mg} / \mathrm{dl}(6.1-8.3 \mathrm{mmol} / \mathrm{L})$. When the patients were stepped down from ICU to post-ICU, blood glucose management was according to GKI sliding scale. postoperatively on arrival at ICU, record of 12-lead long strip ECG of each patient was taken. Then development of AF was screened every morning from the 24 hours ECG recording stored in the memory of ICU monitor and appropriate strips were picked up. In post-ICU ward, ECG strips were taken every morning and whenever any symptom develops.

Data were collected using a preformed data collection sheet from history, clinical examination and laboratory investigations. All data were compiled, screened and checked and entered into a computer to create a data file. The statistical package for the social sciences (SPSS) software (version-22) was used to evaluate all data. Chisquare test, Fisher's test \& student's t test were used for data analysis. Quantitative data were expressed as mean and standard deviation (SD) and comparison between groups were done by student's t test. Qualitative data were expressed as frequency and percentage and comparison was carried by chi-square test \& Fisher's test. For all analytic tests, the level of significance was set at $p<0.05$. The summarized data were presented in the form of tables. Regarding ethical issue Ethical clearance for this study was taken from the Ethical Committee of National Institute of Cardiovascular Diseases.

\section{Results:}

Table I shows that maximum patients (46.7\%) within 51-60 years in Group I and 63.3\% in Group II within $41-50$ years. The mean age of Group-I is $58.50 \pm 6.80 \mathrm{yrs}$. and that of Group-II is $50.53 \pm 6.01$ years. The mean difference between the two groups is statistically significant. The males are predominant in both Groups. 93.3\% patients are male in Group I and $76.7 \%$ in Group II. There is no significant difference between the groups in respect to sex $(p=0.071)$. Maximum postoperative atrial fibrillation (AF) developed in higher age group 61-70 years (61.5\%). there is no significant difference between two groups regarding duration of operation (3.91 $\pm 0.65 \mathrm{VS} 4.0 \pm 0.47)$, peroperative inotropes used $(3.47 \pm 0.51$ VS $3.60 \pm 0.50)$ and peroperative any other arrhythmia $3(10.0 \%)$ VS $4(13.3 \%)$ in both groups respectively.

Table II shows distribution of preoperative variables in two groups. Difference of mean preoperative $\mathrm{HbA} 1 \mathrm{c}$ is significant between two groups. There is no significant difference between Group A and B in hypertension, H/O antiarrhythmic drugs, and NYHA class.

Table-I

Distribution of study population by age $(n=60)$.

\begin{tabular}{|c|c|c|c|c|}
\hline \multirow[t]{2}{*}{ Age (years) } & \multicolumn{2}{|c|}{ Group } & \multirow{2}{*}{$\begin{array}{c}\text { Development } \\
\text { of } \mathrm{AF}\end{array}$} & \multirow[t]{2}{*}{$\mathrm{p}$ value } \\
\hline & $\begin{array}{c}\text { Group-I }(\mathrm{n}=30) \\
\text { No. }(\%)\end{array}$ & $\begin{array}{c}\text { Group-II }(n=30) \\
\text { No. }(\%)\end{array}$ & & \\
\hline $41-50$ & $5(16.7)$ & $19(63.3)$ & $10(41.7)$ & \\
\hline $51-60$ & $14(46.7)$ & $9(30.0)$ & $10(43.5)$ & \\
\hline $61-70$ & $11(36.7)$ & $2(6.7)$ & $8(61.5)$ & \\
\hline Total & $30(100.0)$ & $30(100.0)$ & $28(46.7)$ & \\
\hline Mean \pm SD & $58.50 \pm 6.80$ & $50.53 \pm 6.01$ & & $<0.001^{*}$ \\
\hline
\end{tabular}

Group I: Diabetic patients with $\mathrm{HbA}_{1} \mathrm{c}<7 \%$ undergone OPCAB surgery

Group II: Diabetic patients with $\mathrm{HbA}_{1} \mathrm{c}$ e"7\% undergone OPCAB surgery

Data are analyzed using Student's t-test and are presented as mean \pm SD

*significant 
Table-II

Distribution of the study population by preoperative variables $(n=60)$.

\begin{tabular}{lccc}
\hline Variables & $\begin{array}{c}\text { Group } \\
\text { Group-I (n=30) } \\
\text { No. (\%) }\end{array}$ & $\begin{array}{c}\text { Group-II (n=30) } \\
\text { No. (\%) }\end{array}$ \\
\hline $\begin{array}{l}\text { Preoperative HbA } \text { c }_{1} \\
\text { No of Coronary artery stenosis }\end{array}$ & $6.11 \pm 0.44$ & $7.98 \pm 0.55$ & \\
$\quad$ SVD & $2(6.7)$ & & $<0.001^{*}$ \\
DVD & $9(30.0)$ & $3(3.3)$ & 0.110 \\
TVD & $19(63.3)$ & $26(86.7)$ & \\
Hypertension & $5(16.7)$ & $6(20.0)$ & 0.739 \\
H/O anti arrhythmic drug & $3(10.0)$ & $5(16.7)$ & 0.448 \\
NYHA & & & 0.766 \\
$\quad$ Class III & $23(76.7)$ & $22(73.3)$ & \\
Class IV & $7(23.3)$ & $8(26.7)$ & \\
\hline
\end{tabular}

Group I: Diabetic patients with $\mathrm{HbA1c}<7 \%$ undergone OPCAB surgery

Group II: Diabetic patients with $\mathrm{HbA1c} \geq 7 \%$ undergone OPCAB surgery

Chi square $(\chi 2)$ test is used to analyze Data.

Figure in the parenthesis denotes corresponding percentage.

*significant

Table III shows that development of postoperative AF is significantly higher in Group II compare to Group I. that number of postoperative inotropes used (3.43 \pm 0.50 VS $3.73 \pm 0.45$, $p$ value 0.018$)$ is significantly higher in Group II. Postoperative blood sugar level $(9.87 \pm 1.29$ vs. $10.55 \pm 1.60)$ and ventilation time (in hours $9.17 \pm 1.60$ vs. $9.77 \pm 1.55$ ) are not significantly different between two groups. Regarding postoperative serum electrolytes differences are not statistically significant between two groups, except serum potassium ( $4.44 \pm 0.40 \mathrm{vs}$. $4.76 \pm 0.48, \mathrm{p}=0.006)$ which is higher in group II.

Table IV showed that out of 28 hypertensive patients AF develops in 9 patients which is significantly higher than its normotensive counterpart (2 out of 32 ).

Table $\mathrm{V}$ shows that incidence of postoperative wound infection 8(26.7\%) significantly in Group II compare to Group I.

Multivariate logistic regression analysis regarding presence of postoperative $\mathrm{AF}$ shows that variables like age $(61-70$ years $)(\mathrm{OR}=1.872, \mathrm{p}=0.018)$, preoperative $\mathrm{HbA} 1 \mathrm{c} \geq 7 \%(\mathrm{OR}=19.029, \mathrm{p}=0.002)$ and Hypertension $(\mathrm{OR}=1.091, \mathrm{p}=0.019)$ are significantly associated with increased development of postoperative AF.

Table-III

Association of postoperative AF between two groups $(n=60)$.

\begin{tabular}{lccc}
\hline Postoperative AF & \multicolumn{2}{c}{ Group } & p value \\
\cline { 2 - 4 } & Group-I (n=30) & Group-II (n=30) & \\
\hline Yes & No. (\%) & No. (\%) & $0.010^{*}$ \\
No & $9(30.0)$ & $19(63.3)$ & \\
Total & $21(70.0)$ & $11(36.7)$ & \\
\hline
\end{tabular}

Group I: Diabetic patients with HbA1c $<7 \%$ undergone OPCAB surgery

Group II: Diabetic patients with HbA1c e"7\% undergone OPCAB surgery

Chi square $(\div 2)$ test is used to analyze the Data.

Figure in the parenthesis denotes corresponding percentage.

*significant 
Table-IV

Association of postoperative AF in hypertensive patients $(n=60)$.

\begin{tabular}{lccc}
\hline Hypertension & \multicolumn{2}{c}{ Postoperative AF } & p-value \\
\cline { 2 - 3 } & Yes & No & \\
\hline Yes & $9(32.1)$ & $2(6.3)$ & $0.010^{*}$ \\
No & $19(67.9)$ & $30(93.8)$ & \\
\hline Total & $28(100.0)$ & $32(100.0)$ & \\
\hline
\end{tabular}

Chi square $(\div 2)$ test is to analyze the Data.

Figure in the parenthesis denotes corresponding percentage.

*significant.

Table-V

Distribution of the study by postoperative complications.

\begin{tabular}{lccc}
\hline Postoperative complications & \multicolumn{2}{c}{ Group } & p value \\
\cline { 2 - 3 } & Group-A (n=30) & Group-B (n=30) & \\
\hline Wound infection & No. (\%) & $8(26.7)$ & $0.037^{*}$ \\
Myocardial Infarction & $2(6.7)$ & $2(6.7)$ & 0.150 \\
Ventricular Tachycardia & $0(0)$ & $1(3.3)$ & 0.313 \\
Left ventricular failure & $0(0)$ & $2(6.7)$ & 0.150 \\
None & $0(0)$ & $17(56.7)$ & \\
\hline
\end{tabular}

Group I: Diabetic patients with $\mathrm{HbA1c}<7 \%$ undergone OPCAB surgery

Group II: Diabetic patients with HbA1c e" $7 \%$ undergone OPCAB surgery

Chi square $(\div 2)$ test is used to analyze the Data.

Figure in the parenthesis denoted corresponding percentage.

*significant

Table-VI

Multivariate logistic regression analysis.

\begin{tabular}{lcccccc}
\hline Variables & b & S.E. & p-value & OR & \multicolumn{2}{c}{$95 \%$ CI } \\
\cline { 6 - 7 } & & & & & Lower & Upper \\
\hline Age (61-70 years) & 0.137 & 0.058 & 0.018 & 1.872 & 0.779 & 2.976 \\
Preoperative HbA 1 c $\geq 7 \%$ & 2.946 & 0.974 & 0.002 & 19.029 & 2.822 & 128.31 \\
HTN (yes) & 2.394 & 1.012 & 0.019 & 1.091 & 1.013 & 2.664 \\
No of preoperative inotrope & 0.424 & 0.648 & 0.513 & 0.655 & 0.184 & 2.331 \\
\hline
\end{tabular}

*significant

\section{Discussion:}

The major finding of the present study, which enrolled 60 patients undergone elective off-pump coronary bypass surgery in the Department of Cardiac Surgery, NICVD, Dhaka was that higher preoperative $\mathrm{HbA1c}$ was independently associated with a higher incidence of postoperative AF. Present study showed that the significant association between preoperative $\mathrm{HbA} 1 \mathrm{c}$ level and early postoperative new onset atrial fibrillation after off-pump coronary artery bypass grafting (OPCAB) in diabetic patients.

In our study, diabetes mellitus appeared as an independent risk factor for cardiovascular events after off-pump CABG. Tsuruta et al. in 2011 reported diabetes mellitus as an independent risk factor for cardiovascular events after CABG. ${ }^{12}$

Maximum postoperative atrial fibrillation (AF) developed in higher age group 61-70 years (61.5\%). 
Males were predominant in both Groups. Holkos et al. reported mean age of non-diabetic group $63.0 \pm 10.9$ years and diabetic group $61.6 \pm 10.0$ years, and male predominant in both groups, which correlates well with the present study. ${ }^{6}$

Regarding preoperative HbA1c level in diabetic patient undergone CABG we found that higher A1c level was directly associated with an increased risk of early postoperative new-onset atrial fibrillation. In this study we took HbA1c of $\geq 7 \%$ as a threshold to differentiate between optimal and suboptimal control of glycemia. An $\mathrm{HbA} 1 \mathrm{c}$ level of $6.5 \%$ yields a specificity of $99.6 \%$ and is currently the recommended diagnostic threshold .14-16 Hemoglobin A1c level bears a very close correlation with chronic blood glucose control of diabetic patients,${ }^{17}$ and its main value lies in its use as a predictor of diabetic complications. ${ }^{18}$

In our study, among patients who undergone OPCAB the incidences of other postoperative complications i.e. wound infections, MI, VT, LVF were also higher in the group of patients with a higher preoperative HbA1c ( $\geq 7 \%)$ level. However, these patients were more likely to have associated conditions such as increased age, hypertension and increased requirement of post-operative inotropes. In addition, the number of female patients in this group was higher. Even after adjusting for all these demographic differences, wound infection significantly high in these $\mathrm{HbA} 1 \mathrm{c}$ of $\geq 7 \%$ patients. Our findings have been corroborated by other studies. Elevated HbA1c has been reported to be associated with increased early mortality rates, adverse postoperative outcomes, and shorter longterm survival and others also has reported comparable results. ${ }^{6,18}$ Rates of deep (as well as superficial ${ }^{19}$ sternal wound infection were significantly increased with a higher HbA1c. High HbA1c, in essence, reflects poor glycemic control. There is substantial evidence that poor glycemic control is associated with worse outcomes in patients undergoing CABG. In chronic uncontrolled diabetic state, there may be reduced ventricular contractility and cardiac output. Impaired coronary flow reserve reflecting coronary microvascular dysfunction is common in diabetic patients. ${ }^{20}$

In this study we found that after OPCAB the incidence of postoperative new-onset atrial Fibrillation was significantly higher in patients having preoperative $\mathrm{HbA} 1 \mathrm{c} \geq 7 \%$ compare to those having $<7 \%$. Results of studies carried out by Halkos et al. and Tennyson et al. suggested an increased incidence of atrial fibrillation in diabetic patients is associated with increased preoperative HbA1c level. ${ }^{6}$ Controversial reports are also available in this relevance, though they were confounded by many factors. Some studies have shown that higher HbA1c levels were associated with a reduced incidence of atrial fibrillation. Kinoshita et al. reported that preoperative $\mathrm{HbA1c}$ levels and the development of postoperative atrial fibrillation is inversely related. ${ }^{21}$ In that HbA1c values were significantly lower in patients who developed AF postoperatively [HbA1c 5.8 (5.4-6.3) vs HbA1c 6.1 (5.5-7.2), $\mathrm{P}=0.01] .{ }^{6}$

In this study adjusting multivariate logistic regression analysis among the presence of postoperative $\mathrm{AF}$ and variables like age (61-70 years $)(\mathrm{OR}=1.872, \mathrm{p}=0.018)$, diabetic patients with $\mathrm{HbA1c} \geq 7 \%(\mathrm{OR}=19.029, \mathrm{p}=0.002)$ and hypertension $(\mathrm{OR}=1.091, \mathrm{p}=0.019)$ we found that these are significantly associated with development of postoperative AF. Arsalan et al. ${ }^{3}$ in a prospective study consisting of 3555 patients reported that poor diabetic control is a significant indicator of postCABG complications, and demonstrated a significant increase in the incidence of renal failure, $\mathrm{AF}$, infection, and length of hospital stay in patients with poorly $(\mathrm{HbA1c} \geq 7)$ controlled $\mathrm{HbA} 1 \mathrm{c}$ preoperatively. Selvin et al. demonstrated that for every whole percentage increase in $\mathrm{HbA1c}$, the relative risk of cardiovascular disease increased by $18 \%$ for type 2 diabetes and by $15 \%$ for type 1 diabetes. ${ }^{3,22}$

The insight that a high HbA1c level adversely affects outcome after OPCAB would allow surgeons to risk stratify patients before operation and to take required measures. As because $\mathrm{HbA} 1 \mathrm{c}$ is a modifiable factor, patients who are candidates for elective OPCAB with stable angina and without any anatomically critical lesions, attempts should be made to control blood glucose levels over a period of time, thereby reducing HbA1c levels preoperatively in the hope of best possible postoperative result.

\section{Conclusion:}

Our study showed that preoperative higher HbA1c level was associated with increased development of 
new onset early postoperative atrial fibrillation in diabetic patients undergone OPCAB. Despite conventional glycemic control, HbA1c level can be used as a reliable and modifiable factor to achieve adequate preoperative diabetes control and thus reduction of the occurrence of postoperative atrial fibrillation after isolated OPCAB for better outcome.

\section{Limitations}

This study had several limitations. The sample size was small and sampling technique was not randomized. The study population was selected from a single centre, so that the result might not reflect the exact picture of the whole country.

\section{Conflict of interest: None.}

\section{References:}

1. Boccara F, Cohen A. Interplay of diabetes and coronary heart disease on cardiovascular mortality. Heart 2004; 13(3): 1371-1374.

2. Wijeysundera DN, Beattie WS, Djaiani G, Rao V, Borger MA, Karkouti K, et al. Off-pump coronary artery surgery for reducing mortality and morbidity: metaanalysis of randomized and observational studies. J Am Coll Cardiol 2005; 46(5): 872-882.

3. Arslan U, Memetoðlu ME, Kutlu R, Erbasan O, Tort M, Çalýk ES, et al. Preoperative HbA1c level in prediction of short-term morbidity and mortality outcomes following coronary artery bypass grafting surgery. Russian OMJ 2015; 4: e0204.

4. Asida SM, Atalla MMM, Gad GS, Eisa KM, Mohamed HS. Effect of perioperative control of blood glucose level on patient's outcome after anesthesia for cardiac surgery. Egypt J Anaesth 2013; 29( 1): 71-76.

5. Tekumit H, Cenal AR, Polat A, Uzun K, Tataroglu C, Akinci E. Diagnostic value of hemoglobin A1c and fasting plasma glucose levels in coronary artery bypass grafting patients with undiagnosed diabetes mellitus. Ann Thorac Surg 2010; 89(5): 1482-1487.

6. Halkos ME, Puskas JD, Lattouf OM, Kilgo P, Kerendi F, Song HK, et al. Elevated preoperative hemoglobin A1c level is predictive of adverse events after coronary artery bypass surgery. J Thorac Cardiovasc Surg 2008; 136(3): 631-640.

7. Olson DE, Rhee MK, Herrick K, Ziemer DC, Twombly JG, Phillips LS. Screening for diabetes and pre-diabetes with proposed A1C-based diagnostic criteria. Diabetes Care 2010; 33(10):.2184-2189.

8. Helgadottir S, Sigurdsson MI, Ingvarsdottir IL, Arnar DO, Gudbjartsson T. Atrial fibrillation following cardiac surgery: risk analysis and long-term survival. $J$ Cardiothorac Surg 2012; 7(1): 87.

9. Surer S, Seren M, Saydam O, Bulut A, Kiziltepe U. The relationship between $\mathrm{HbA1c} \&$ atrial fibrillation after off-pump coronary artery bypass surgery in diabetic patients. Pak J Med Sci 2016; 32(1): 59.

10. Attaran S, Shaw M, Bond L, Pullan MD, Fabri BM. Atrial fibrillation postcardiac surgery: a common but a morbid complication. Interact Cardiovasc Thorac Surg 2011; 12(5): 772-777.

11. Zheng J, Cheng J, Wang T, Zhang Q, Xiao X. Does HbA1c Level Have Clinical Implications in Diabetic Patients Undergoing Coronary Artery Bypass Grafting? A Systematic Review and Meta-Analysis. Int $J$ Endocrinol 2017; 13(3): 1-8.

12. Tsuruta R, Miyauchi K, Yamamoto T, Dohi S, Tambara K, Dohi T, et al. Effect of preoperative hemoglobin A1c levels on long-term outcomes for diabetic patients after off-pump coronary artery bypass grafting. $J$ Cardiol 2011; 57(2): 181-186.

13. Zhang Q, Liu T, Ng CY, Li G. Diabetes mellitus and atrial remodeling: mechanisms and potential upstream therapies. Cardiovasc Ther 2014; 32(5): 233-241.

14. Subramaniam B, Lerner A, Novack V. Increased glycemic variability in patients with elevated preoperative HbA1C predicts adverse outcomes following coronary artery bypass grafting surgery. Anesth Analg 2014; 118: 277-287.

15. McGinn JT Jr, Shariff MA, Bhat TM. Prevalence of dysglycemia among coronary artery bypass surgery patients with no previous diabetic history. $J$ Cardiothorac Surg 2011; 6: 104.

16. Sato H, Carvalho G, Sato T, Lattermann R, Matsukawa $\mathrm{T}$, Schricker T. The association of preoperative glycemic control, intraoperative insulin sensitivity, and outcomes after cardiac surgery. J Clin Endocrinol Metab 2010; 95: 4338-4344.

17. Nathan DM, Kuenen J, Borg R, Zheng H, Schoenfeld D, Heine RJ. A1c-Derived Average Glucose Study Group. Translating the A1C assay into estimated average glucose values. Diabetes Care 2008; 31:14731478.

18. Saudek CD, Derr RL, Kalyani RR. Assessing glycemia in diabetes using self-monitoring blood glucose and hemoglobin A1c. JAMA 2006; 295: 1688-1697.

19. Alserius T, Anderson RE, Hammar N, Nordqvist T, Ivert T. Elevated glycosylated hemoglobin (HbA1c) is a risk marker in coronary artery bypass surgery. Scand Cardiovasc J 2008; 42: 392-398.

20. Sorrentino A, Borghetti G, Zhou Y, Cannata A, Meo M, Signore S, et al. Hyperglycemia induces defective Ca2+ homeostasis in cardiomyocytes. Am $J$ Physiol Heart Circ Physiol 2016; 312(1): H150-H161.

21. Kinoshita T, Asai T, Suzuki T, Kambara A, Matsubayashi K. Preoperative hemoglobin A1c predicts atrial fibrillation after off-pump coronary bypass surgery. Eur $J$ Cardiothorac Surg 2012;41(1): 102-107.

22. Selvin E, Marinopoulos S, Berkenblit G, Rami T, Brancati FL, Powe NR, et al. Meta-analysis: glycosylated hemoglobin and cardiovascular disease in diabetes mellitus. Ann Intern Med 2004; 141(6): 421-431. 